\title{
Long non-coding RNA RP5-833A20.1 inhibits proliferation, metastasis and cell cycle progression by suppressing the expression of NFIA in U251 cells
}

\author{
CHUN-MIN KANG ${ }^{1 *}$, YAN-WEI HU $^{1 *}$, YING NIE $^{2}$, JIA-YI ZHAO $^{1}$, SHU-FEN LI ${ }^{1}$, \\ SHUAI CHU ${ }^{1}$, HAI-XIA LI ${ }^{1}$, QING-SHUI HUANG ${ }^{1}$ and YU-RONG QIU ${ }^{1}$ \\ ${ }^{1}$ Laboratory Medicine Center, Nanfang Hospital, Southern Medical University, Guangzhou, Guangdong 510515; \\ ${ }^{2}$ Department of Anesthesiology, Guangdong 999 Brain Hospital, Guangzhou, Guangdong 510510, P.R. China
}

Received August 27, 2015; Accepted August 16, 2016

DOI: $10.3892 / \mathrm{mmr} .2016 .5854$

\begin{abstract}
Early reports suggest that nuclear factor IA (NFIA) is important in the pathogenesis of glioma. Our previous study demonstrated that the long non-coding RNA (lncRNA), RP5-833A20.1, suppressed the expression of NFIA in THP-1 macrophage-derived foam cells. However, the effect and possible mechanism of RP5-833A20.1 on glioma remains to be fully elucidated, and whether the NFIA-dependent pathway is involved in its progression has not been investigated. In the present study, the mechanisms by which RP5-833A20.1 regulates the expression of NFIA in glioma were investigated. The expression levels of RP5-833A20.1 and NFIA were determined in U251 cells and clinical samples using reverse transcription-quantitative polymerase chain reaction (PCR) analysis. The effects of RP5-833A20.1 on cell proliferation, invasion, cell cycle and apoptosis were evaluated using in vitro assays. The potential changes in protein expression were investigated using western blot analysis. The methylation status of the $\mathrm{CpG}$ island in the NFIA promoter was determined using bisulfite PCR (BSP) sequencing. It was found that the expression of RP5-833A20.1 was downregulated, whereas the expression of NFIA was upregulated in glioma tissues, compared with corresponding adjacent nontumor tissues from 20 patients with glioma. The overexpression of RP5-833A20.1 inhibited proliferation and cell cycle progression, and induced apoptosis in the U251 cells. The mRNA and protein levels of NFIA were markedly inhibited by overexpression of RP5-833A20.1 in the U251 cells. The overexpression of RP5-833A20.1 increased
\end{abstract}

Correspondence to: Professor Yu-Rong Qiu, Laboratory Medicine Center, Nanfang Hospital, Southern Medical University, 1838 North Guangzhou Avenue, Guangzhou, Guangdong 510515, P.R. China E-mail: qiuyuronggz@126.com

*Contributed equally

Key words: long non-coding RNA RP5-833A20.1, nuclear factor IA, glioma, U251 cell, methylation the expression of microRNA-382-5p in the U251 cells. The BSP assay revealed that the overexpression of RP5-833A20.1 enhanced the methylation level of the NFIA promoter. These results demonstrated that RP5-833A20.1 inhibited tumor cell proliferation, induced apoptosis and inhibited cell-cycle progression by suppressing the expression of NFIA in U251 cells. Collectively, these results indicated RP5-833A20.1 as a novel therapeutic target for glioma.

\section{Introduction}

Gliomas are the most frequent type of primary tumor in the brain and account for $50-60 \%$ of all brain tumors worldwide (1). Despite advances in cancer treatment, this statistic has not changed significantly $(2,3)$. Previous reports have suggested that several genes contribute to the pathogenesis of glioma, including protein-coding genes $(4,5)$, microRNAs (miRNAs) (6) and long non-coding RNAs (lncRNAs) $(7,8)$. However, the mechanisms of the majority of genes in glioma remain to be elucidated. Therefore, an improved understanding of the molecular mechanisms involved in the development, progression and metastasis of glioma is essential for identifying novel prognostic molecular markers and designing more individualized and effective therapeutic strategies.

lncRNAs, which are a subgroup of non-coding RNAs, are non-protein coding transcripts with a length of $>200$ nucleotides $(9,10)$. Previous reports have shown that lncRNAs have multifunctional roles in modulating embryonic pluripotency, differentiation, development and various diseases, particularly in cancer (11-13). IncRNAs may be classified according to their mode of action and their functions in cells, including genetic imprinting (14,15), modulating the cancer epigenome (9), serving as molecular decoys (16) and post-transcriptional regulation (10). Accumulating evidence has shown that lncRNA expression profiling may facilitate the diagnosis and prognosis of human cancer, including bladder cancer (17), leukemia (18), breast cancer (9) and rectal cancer (19), suggesting that lncRNAs may serve as effective therapeutic targets for intervention. Previous evidence indicates that lncRNAs are important in the pathogenesis of glioma, including HOTAIR (20), H19 (21) and Linc-POU3F3 (8). Although thousands of lncRNAs have 
been annotated, only a few lncRNAs have been functionally characterized in glioma.

Nuclear factor IA (NFIA), a member of the NFI family, is essential in glial development in the central nervous system; it specifies glial identity, maintains glial progenitors and regulates astrocyte differentiation $(22,23)$. Increasing evidence has shown that NFIA is involved in and may be central in a variety of biological processes through complicated mechanisms in glioma $(24,25)$. For example, Glasgow et al (26) first characterized the miR-223/NFIA axis in glioma. The RP5-833A20.1 lncRNA is located in intron 2 of the NFIA gene and has an opposite transcription direction to NFIA. Our previous investigations showed that NFIA is important in the progression of atherosclerosis, which is regulated by RP5-833A20.1 (27). However, whether NFIA is targeted by RP5-833A20.1 in glioma remains to be elucidated.

The present study aimed to examine the role of RP5-833A20.1 in glioma and to investigate whether NFIA is targeted by RP5-833A20.1. It was found that the expression of RP5-833A20.1 was decreased, whereas the expression of NFIA was increased in glioma tissues, compared with adjacent normal tissues. Furthermore, the present study investigated the effects of the expression of RP5-833A20.1 on U251 cell phenotype in vitro via a gain-of-function experiment. It was shown that the overexpression of RP5-833A20.1 suppressed the expression of NFIA, promoted the expression of miR-382-5p and enhanced the methylation level of NFIA in the U251 cells. These results indicated that RP5-833A20.1 may be a novel therapeutic target for glioma.

\section{Materials and methods}

Human samples. Samples of human glioma and adjacent healthy tissues were obtained from 20 patients (11 male

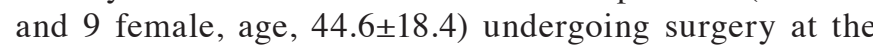
Department of Neurosurgery, Nanfang Hospital of Southern Medical University (Guangzhou, China). None of the patients had received prior chemotherapy or biotherapy, and diagnoses were confirmed pathologically in all cases. Central glioma tissues and adjacent nontumor tissues, located $2 \mathrm{~cm}$ from the center in the same patient were collected. All specimens were snap frozen at the time of surgery and stored in liquid nitrogen. The samples were collected with informed consent from patients and ethical consent was granted from the Committees for Ethical Review of Research involving Human Subjects of Southern Medical University.

RNA extraction and RT-qPCR assays. Total RNA from the cultured cells or human tissues was extracted using TRIzol reagent (Invitrogen; Thermo Fisher Scientific, Inc., Waltham, MA, USA) in accordance with the manufacturer's protocol. Prior to the addition of TRIzol, the tissues were ground using liquid nitrogen. The miRNAs involved in putatively regulating NFIA were detected using the All-in-One ${ }^{\mathrm{TM}}$ miRNA RT-qPCR kit (GeneCopoeia, Rockville, MD, USA) according to the manufacturer's protocol in $20 \mu \mathrm{l}$ reaction volumes. Prior to the addition of TRIzol, the tissues were ground with liquid nitrogen. cDNA was generated from $1000 \mathrm{ng}$ of total RNA and $2 \mu \mathrm{lcDNA}$ were used for PCR analysis. The amplification conditions were as follows: Stage $1,95^{\circ} \mathrm{C}$ for $30 \mathrm{sec}$; stage 2, $95^{\circ} \mathrm{C}$ for $3 \mathrm{sec}$ and then $60^{\circ} \mathrm{C}$ for $30 \mathrm{sec}, 40$ cycles; stage $3,95^{\circ} \mathrm{C}$ for $15 \mathrm{sec}, 60^{\circ} \mathrm{C}$ for $1 \mathrm{~min}, 95^{\circ} \mathrm{C}$ for $15 \mathrm{sec}, 60^{\circ} \mathrm{C}$ for $15 \mathrm{sec}$. The RT-qPCR was performed on an ABI 7500 Fast Real Time PCR system (Applied Biosystems; Thermo Fisher Scientific, Inc.). The expression of U6 RNA was used as an endogenous control (28). The mRNA levels were evaluated using the ABI 7500 Fast Real-Time PCR system with SYBR green detection chemistry (Takara Bio, Inc., Shiga, Japan). The expression of GAPDH was used as an internal control (29). Quantitative measurements were determined using the $\Delta \Delta \mathrm{Cq}$ method (30). All samples were measured in triplicate and the mean value was considered for comparative analysis. The sequences of the primers used are listed in Table I.

Cell line and culture conditions. U251 cells were obtained from American Type Culture Collection (Manassas, VA, USA) and maintained according to the supplier's recommendation. The U251 human glioma cells were maintained in Dubecco's modified Eagle's medium (DMEM; Gibco; Thermo Fisher Scientific, Inc.) with high glucose and sodium pyruvate, supplemented with $10 \%$ fetal bovine serum (FBS; Gibco; Thermo Fisher Scientific, Inc.) and antibiotics (100 U/ml penicillin and $100 \mathrm{mg} / \mathrm{ml}$ streptomycin). The cells were maintained in a humidified incubator at $37^{\circ} \mathrm{C}$ with $5 \% \mathrm{CO}_{2}$.

Lentiviral construction and cell transfection. Packed empty lentivirus (LV) vectors (Landbiology, Guangzhou, China) with green fluorescent protein (GFP; LV-Mock), an LV-mediated 1ncRNA RP5-833A20.1-overexpression vector (LV-RP5-833A20.1), and an LV-mediated lncRNA RP5-833A20.1-knockdown vector (LV-siRNA-RP5-833A20.1) with GFP were prepared as described previously (31). The $\mathrm{U} 251$ cells were incubated in 6 -well plates for $24 \mathrm{~h}$ at a density of $2 \times 10^{6}$ cells/well and then were transfected using DMEM and polybrene reagents (Santa Cruz Biotechnology, Inc., Dallas, TX, USA) according to the manufacturer's protocol at a multiplicity of infection of 1 . The U251 human glioma cells were maintained in Dubecco's modified Eagle's medium (DMEM) with high glucose and sodium pyruvate, supplemented with $10 \% \mathrm{FBS}$ and antibiotics (100 U/ml penicillin and $100 \mathrm{mg} / \mathrm{ml}$ streptomycin), and plus $2 \mu \mathrm{g} / \mathrm{ml}$ puromycin for 2 weeks to gain stable clones. The cells were maintained in a humidified incubator at $37^{\circ} \mathrm{C}$ with $5 \% \mathrm{CO}_{2}$. The expression level of RP5-833A20.1 was determined using RT-qPCR analysis.

Cell proliferation assays. For the cell proliferation assays, the U251 cells were seeded in 96-well plates at the density of $2 \times 10^{3}$ cells/well. Cell Counting Kit-8 (Dojindo Laboratories, Kumamoto, Japan) solution $(10 \mu \mathrm{l})$ was added to each well and the cells were incubated for $1.5 \mathrm{~h}$ at $37^{\circ} \mathrm{C}$. The absorbance at $450 \mathrm{~nm}$ was recorded using a Thermo Multiskan MK3 reader (Thermo Fisher Scientific, Inc.). A total of five replicate wells were set up in each group and five independent experiments were performed.

Cell invasion assays. For the invasion assays, $5 \times 10^{4}$ cells in $200 \mathrm{ml}$ serum-free medium were seeded into the upper chamber of a Transwell insert (8-mm pore size; EMD Millipore, Billerica, MA, USA) coated with Matrigel. The lower chamber was filled with 600 liters medium containing 10\% FBS. Following 
Table I. Oligonucleotide sequences used in the present study.

\begin{tabular}{ll}
\hline Gene & \multicolumn{1}{c}{ Sequence } \\
\hline NFIA-F & 5'-AGGTCTTTACCCAGCACATC \\
& CTC-3' \\
NFIA-R & 5'-TCCACTTGACTGACTGCCAC \\
& TTC-3' \\
GAPDH-F & 5'-GCACCGTCAAGGCTGAGAAC-3' \\
GAPDH-R & 5'-TGGTGAAGACGCCAGTGGA-3' \\
RP5-833A20.1-F & 5'-CATGAGCCACAGCAGTAAGC-3' \\
RP5-833A20.1-R & 5'-GGAGAACATGGCAGAAATCA-3' \\
RP5-833A20.1-RT & 5'-GAAAGGAAGGCATCCAACTT-3' \\
U6-F & 5'-CTCGCTTCGGCAGCACA-3' \\
U6-R & 5'-AACGCTTCACGAATTTGCGT-3' \\
U6-RT & 5'-AACGCTTCACGAATTTGCGT-3' \\
BSP-NFIA-F & 5'-AGGATTTTTAATTTTTGGTTT \\
BSP-NFIA-R & ATATTAGTG-3' \\
& 5'-AAAAAAAACCTTACCC \\
& CCTTCT-3'
\end{tabular}

NFIA, nuclear factor IA; BSP, F, forward; R, reverse; RT, reverse transcription.

incubation in a humidified incubator at $37^{\circ} \mathrm{C}$ with $5 \% \mathrm{CO}_{2}$ for $12 \mathrm{~h}$, the cells remaining on the upper membrane were removed with a cotton swab. The cells, which had migrated or invaded through the membrane were stained with methanol and $0.1 \%$ crystal violet, images were captured, and the cells were counted using a BX51 microscope (Olympus, Tokyo, Japan). Invasion was assessed by counting the number of stained cell nuclei from 10 randomly selected fields per filter in each group (magnification, $\mathrm{x} 400$ ), with the cell counts expressed as the mean number of cells per field of view. Three independent experiments were performed in triplicate.

Flow cytometric analysis of apoptosis. The U251 cells were harvested $48 \mathrm{~h}$ following transfection and resuspended $100 \mu \mathrm{l}$ of the solution $\left(1 \times 10^{5}\right.$ cells) to a $5 \mathrm{ml}$ culture tube and add $5 \mu 1$ of FITC Annexin V (BD Biosciences, San Jose, CA, USA) and $5 \mu 1 \mathrm{PI}$ (BD Biosciences). Next, the cells were gently vortexed and incubated for $15 \mathrm{~min}$ at $25^{\circ} \mathrm{C}$ in the dark, $400 \mu \mathrm{l}$ of $1 \mathrm{X}$ Binding Buffer was added to each tube. The results were analyzed using a flow cytometer (FACScan; BD Biosciences) within 1 h. Cell Quest version 6.0 (BD Biosciences) was used to analyze the results. All samples were assayed in triplicate.

Cell cycle distribution. The treated U251 cells were trypsinized, fixed in $70 \%$ ethanol, washed twice with phosphate-buffered saline (PBS), and then labeled with propidium iodide (Nanjing KeyGen Biotech Co., Ltd., Nanjing, China) in the presence of $30 \mathrm{KU} / \mathrm{ml}$ RNase A (KeyGen Biotech Co., Ltd.) for $30 \mathrm{~min}$ in the dark $(50 \mathrm{~g} / \mathrm{ml})$. The samples were run on a FACScan flow cytometer (BD Biosciences), and the percentages of cells within each phase of the cell cycle were analyzed using Cell Quest version 6.0.
Western blot analysis. The cells were washed twice with ice-cold PBS and the cell lysates were harvested using a KeyGen Biotech Whole Cell Lysis Assay kit (KeyGen Biotech Co., Ltd.) according to the manufacturer's protocol. The proteins were quantified by KeyGEN Bradford protein quantitation assay (KeyGen Biotech Co., Ltd.) and $50 \mu \mathrm{g}$ protein per lane was fractionated by $12 \%$ SDS-PAGE, transferred onto a PVDF membrane, blocked with $5 \%$ bovine serum albumin (Beyotime Institute of Biotechnology, Haimen, China) for $1 \mathrm{~h}$ at room temperature and immunoblotted with primary antibodies overnight at $4^{\circ} \mathrm{C}$. Following incubation with the corresponding secondary antibodies conjugated to horseradish peroxidase, the signals of the membranes were detected by chemiluminescence western blotting substrate (Thermo Fisher Scientific, Inc.). The band intensity of western blotting and the normalization were analyzed using ImageJ version 1.6.0 software (National Institutes of Health, Bethesda, MD, USA). The primary antibodies used were obtained from Abcam (Cambridge, UK) as follows: NFIA (cat. no. ab41851; 1:1,000); p53 (cat. no. ab31333; 1:1,000); p21 (cat. no. ab47452; 1:1,000); PAI-1 (cat. no. ab66705; $1: 1,000$ ) and $\beta$-actin (cat. no. ab8227; 1:2,000). The secondary antibody used was goat anti-rabbit IgG (cat. no. bs-0295G; 1:5,000; BIOSS, Beijing, China).

Bisulfite PCR sequencing (BSP). To assess the methylation level of the NFIA gene promoter, U251 cells with knocked down RP5-833A20.1 or transfected with a short hairpin negative control vectors (LAND) were used. Genomic DNA was isolated using a Promega wizard genomic DNA purification kit (Promega, Madison, MA, USA) according to the manufacturer's protocol. DNA modification was performed using an EpiTect Bisulfite kit (Qiagen, Shanghai, China) to convert unmethylated cytosines to uracils. The PCR was performed using the aforementioned protocol. Following BSP, the PCR products were used for cloning and sequencing. The sequences of the BSP primers are listed in Table I.

Statistical analysis. All experiments were performed three times. Data are presented as the mean \pm standard deviation and analyzed using SPSS 13.0 software (SPSS, Inc., Chicago, IL, USA) with Student's $t$-test or one-way analysis of variance. $\mathrm{P}<0.05$ was considered to indicate a statistically significant difference.

\section{Results}

RP5-833A20.1 is downregulated and NFIA is upregulated in glioma. In our previous study, it was shown that the RP5-833A20.1/miR-382-5p/NFIA pathway is essential for the regulation cardiovascular disease (27). Several studies have shown that NFIA is important in glioma $(25,26)$. Thus, the present study hypothesized that RP5-833A20.1 may also function in glioma by regulating the expression of NFIA. To confirm this, the present study examined the RNA expression levels of RP5-833A20.1 and NFIA in 20 paired glioma and adjacent nontumor tissue samples. The expression of RP5-833A20.1 was significantly downregulated $(\mathrm{P}<0.01)$ in $80 \%(16 / 20)$ of the cancerous tissues, compared with the paired adjacent nontumor tissues (Fig. 1A). The expression of 
A

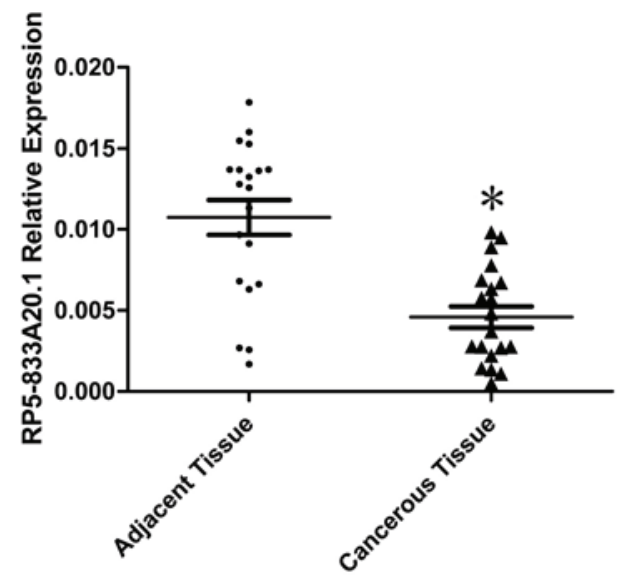

B

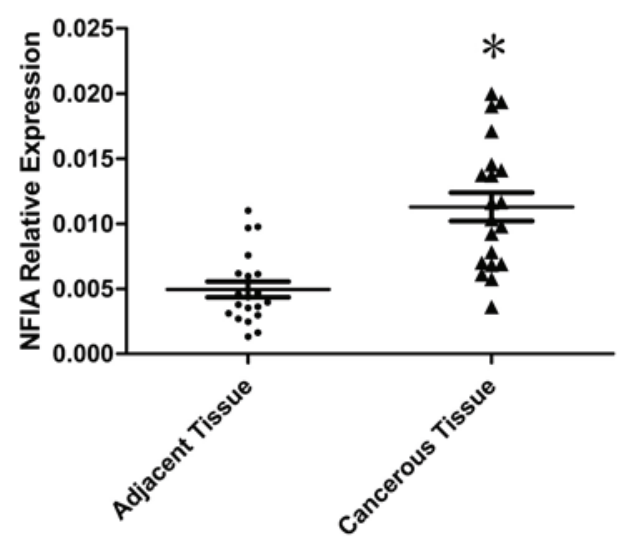

Figure 1. RP5-833A20.1 is downregulated and NFIA is upregulated in glioma. Results are presented as the fold change in tumor tissues relative to normal tissues. (A) RP5-833A20.1 was downregulated in tumor tissues, compared with paired adjacent noncancerous tissues in human glioma $(\mathrm{n}=20)$. Expression levels of RP5-833A20.1 were examined using reverse transcription-quantitative polymerase chain reaction analysis and normalized to U6. "P<0.01. (B) NFIA was upregulated in tumor tissues, compared with paired adjacent noncancerous tissues in human glioma $(\mathrm{n}=20)$. Expression of NFIA was normalized to GAPDH. ${ }^{*} \mathrm{P}<0.01$. NFIA, nuclear factor IA.

A

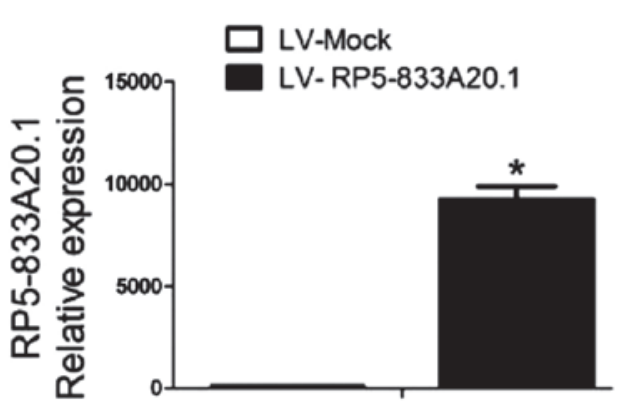

C

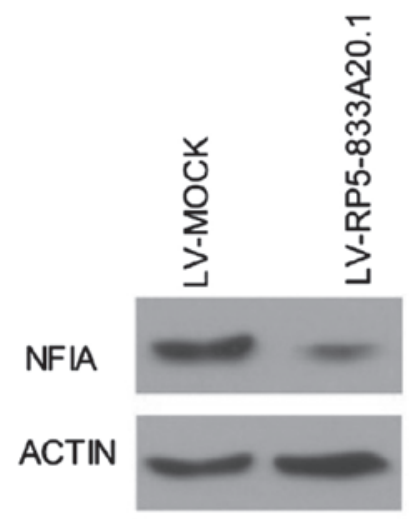

B

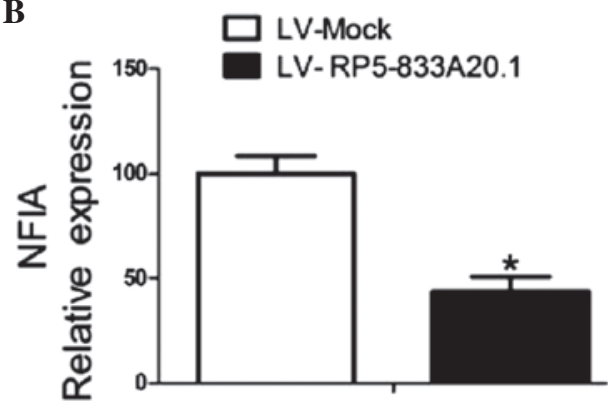

D

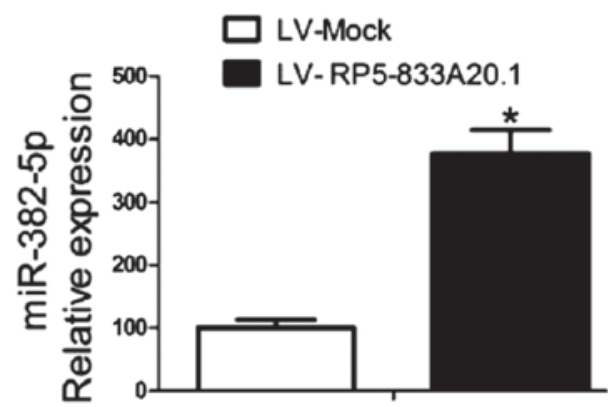

Figure 2. RP5-833A20.1 suppresses the expression of NFIA and promotes the expression of miR-382-5p in U251 cells. (A) Expression of RP5-833A20.1 (mean \pm standard deviation) in U251 cells stably infected with LV encoding RP5-833A20.1. Expression of the RP5-833A20.1 was significantly elevated in the LV-RP5-833A20.1 cells. Expression of RP5-833A20.1 was normalized to that of U6 ( $=5$; $\left.{ }^{*} \mathrm{P}<0.05\right)$. (B) mRNA expression of NFIA was also significantly downregulated. Expression of NFIA was normalized to that of GAPDH ( $\left.=5 ;{ }^{*} \mathrm{P}<0.05\right)$. (C) Western blot analysis of NFIA in U251 cells. The protein level of NFIA was markedly downregulated $(n=5 ; \mathrm{P}<0.05)$. (D) Overexpression of RP5-833A20.1 in the U251 cells increased the expression of miR-382-5p. * $<0.05$. LV, lentivirus; NFIA, nuclear factor IA; miR, microRNA.

NFIA was significantly upregulated $(\mathrm{P}<0.01)$ in $90 \%(18 / 20)$ of the cancerous tissues, compared with the paired adjacent nontumor tissues (Fig. 1B).

RP5-833A20.1 suppresses the expression of NFIA and promotes the expression of miR-382-5p in U251 cells. In our previous study, it was found that RP5-833A20.1 suppressed the expression of NFIA by promoting the expression of
miR-382-5p in THP-1 macrophages (27). The present study examined whether RP5-833A20.1 regulates the expression of NFIA by promoting miR-382-5p in U251 cells. Lentivirus-mediated overexpression of RP5-833A20.1 in the U251 cells(Fig. 2A) markedly inhibited the mRNA and protein expression levels of NFIA (Fig. 2B and C), whereas overexpression of RP5-833A20.1 increased the expression of miR-382 in the U251 cells (Fig. 2D). These results indicated 
A

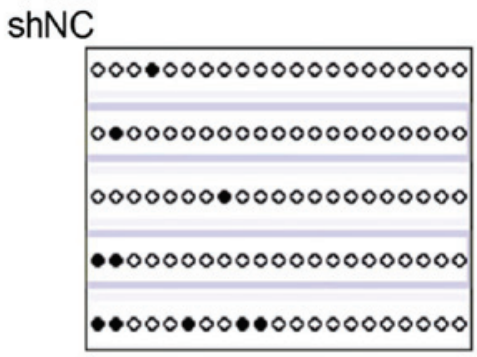

shRP5-833A20.1

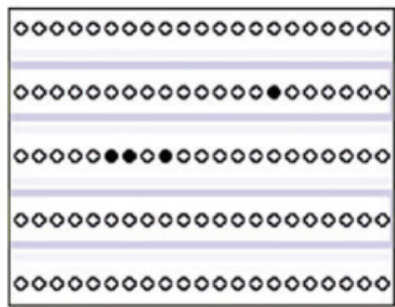

B

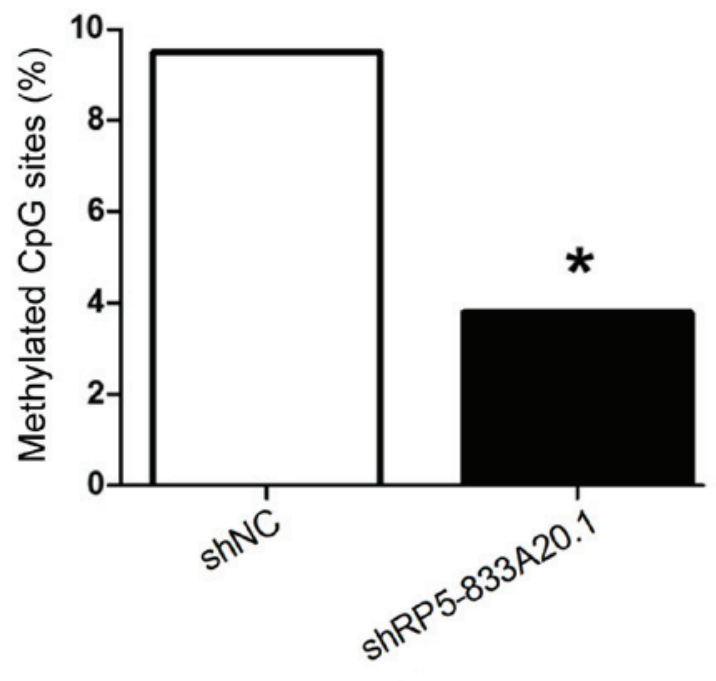

Figure 3. RP5-833A20.1 enhances the methylation level of the NFIA promoter. (A) BSP analysis of RP5-833A20.1 in U251 cells. RP5-833A20.1 was knocked down, which decreased the level of methylation. Open and filled circles represent unmethylated and methylated CpG sites, respectively. (B) Knock down of RP5-833A20.1 decreased the percentage of methylated CpG sites, compared with the control (3.8, vs. 9.5\%, respectively; $\left.{ }^{*} \mathrm{P}<0.05\right)$. NFIA, nuclear factor IA; shNC, short hairpin negative control; BSP, bisulfate polymerase chain reaction.

A

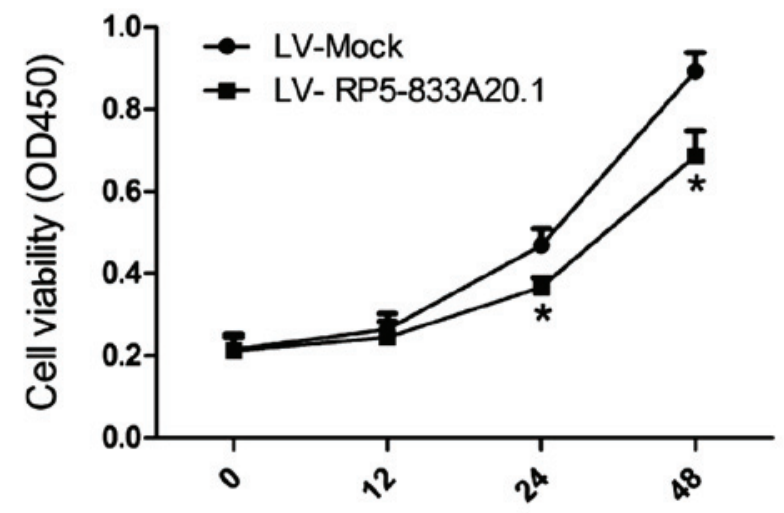

B

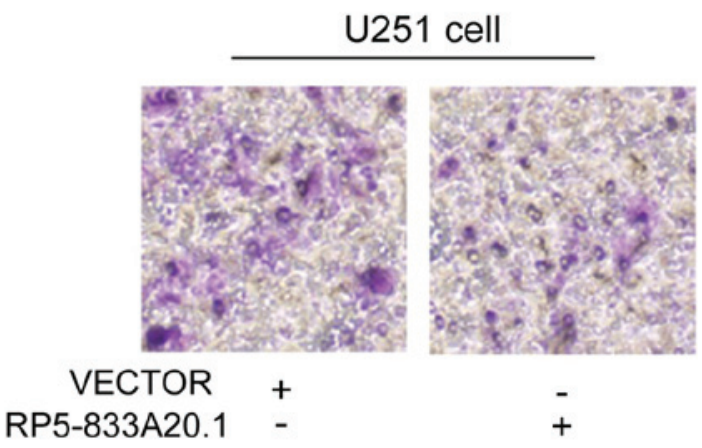

C

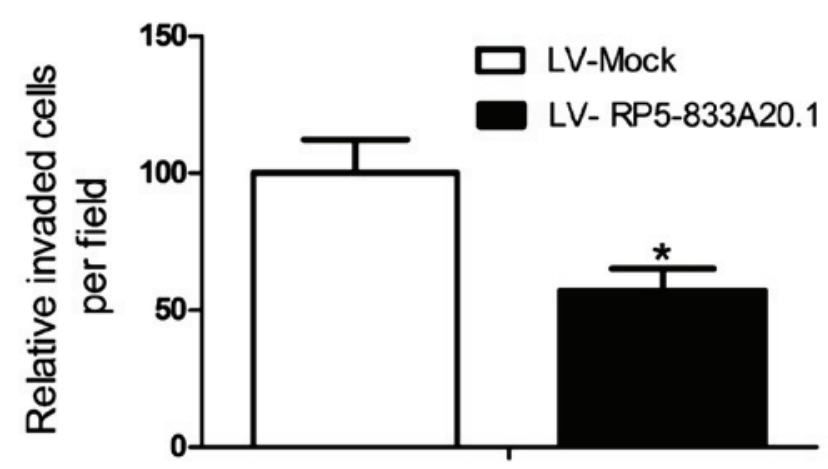

Figure 4. RP5-833A20.1 inhibits cell proliferation and invasion in U251 cells. (A) Cell growth rates were determined by performing Cell Counting Kit-8 proliferation assays. The overexpression of RP5-833A20.1 in U251 cells significantly inhibited cell proliferation, compared with the control cells. Error bars indicate the standard deviation. ${ }^{*} \mathrm{P}<0.05$. (B) Representative images (magnification, $\mathrm{x} 400$ ) and (C) numbers of invasive cells per high-power field. The invasive ability of the U251 cells was inhibited by the overexpression of RP5-833A20.1. Error bars indicate the standard deviation. " $\mathrm{P}<0.05$. LV, lentivirus; OD, optical density.

that RP5-833A20.1 suppressed the expression of NFIA in the U251 cells and that miR-382-5p may be involved in this process.
RP5-833A20.1 enhances the methylation level of the NFIA promoter. Increasing evidence has confirmed that lncRNAs can regulate the DNA methylation of protein-coding genes 
A
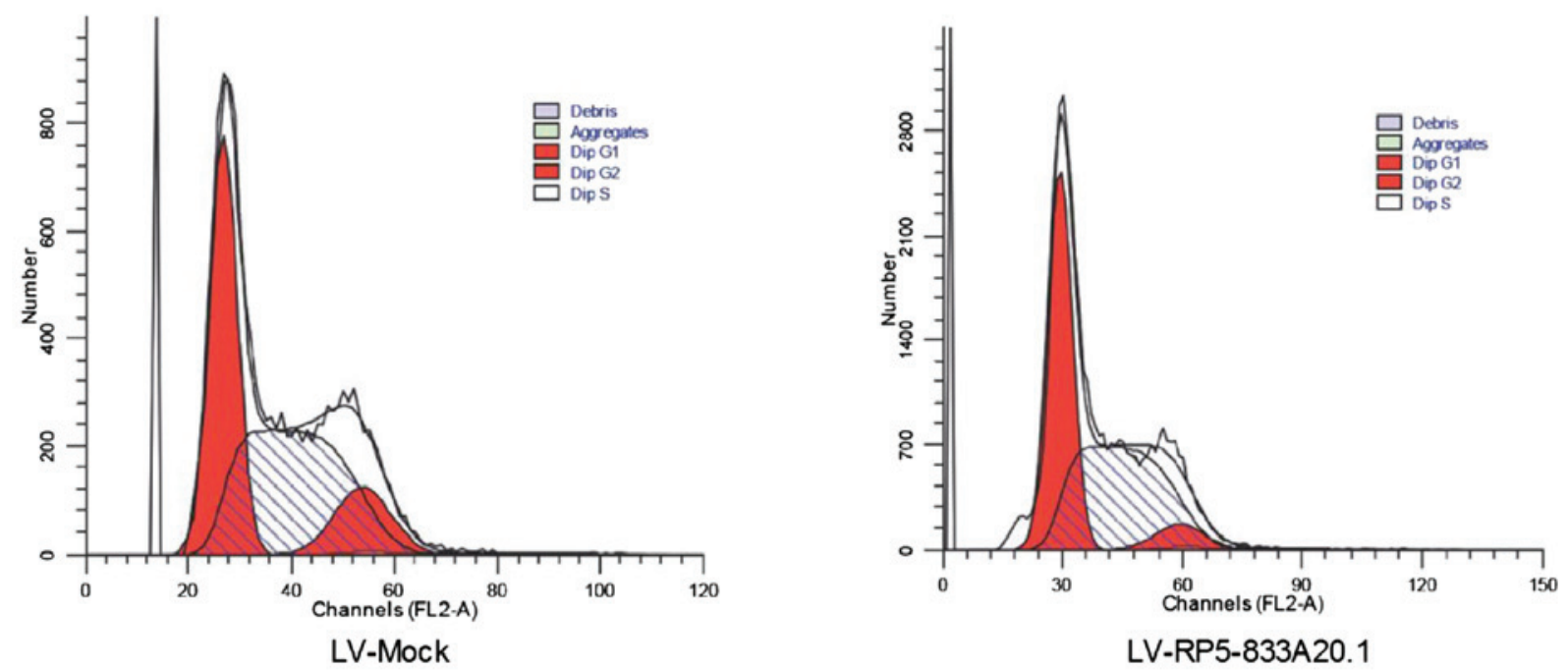

B

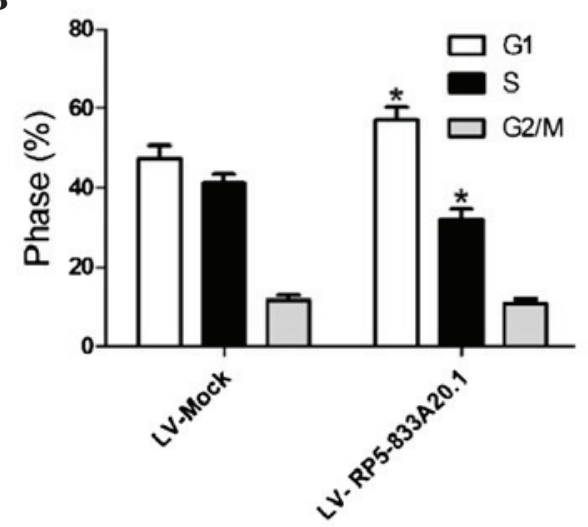

C

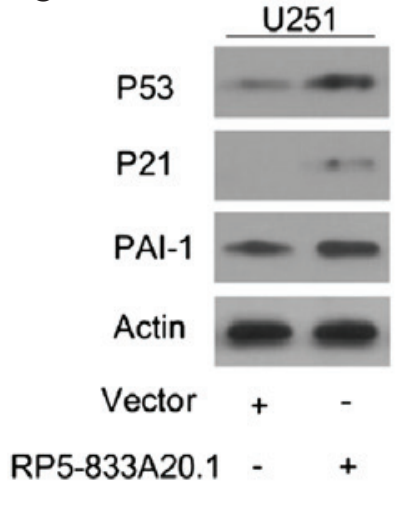

D

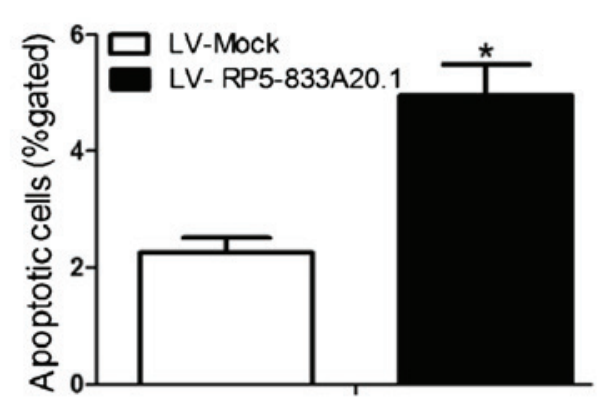

Figure 5. RP5-833A20.1 inhibits cell cycle progression and induces cellular apoptosis. (A and B) FACS analysis showed a significant decrease and increase in the number of cells in the S and G1 phase, respectively, in U251 cells overexpressing RP5-833A20.1. "P<0.05, vs. control. (C) Western blot analysis relvealed that overexpression of RP5-833A20.1 in the U251 cells increased the expression of cell cycle-associated proteins. (D) Cells overexpressing RP5-833A20.1 were stained with a combination of annexin V and propidium iodide, and analyzed using FACS. Cells positive for annexin V staining were counted as apoptotic cells. The percentage of apoptotic cells is shown. " $\mathrm{P}<0.05$. LV, lentivirus; PAI-1, plasminogen activator inhibitor 1.

during the development of disease $(11,32,33)$. To assess the role of RP5-833A20.1 in the regulation of DNA methylation, the present study assessed the methylation level of the NFIA gene promoter using BSP. As shown in Fig. 3A and B, the knock down of RP5-833A20.1 decreased the methylation level of the NFIA promoter in the U251 cells, compared with the control $(3.8$, vs. $9.5 \%$, respectively; $\mathrm{P}<0.05)$. These results indicated that RP5-833A20.1 repressed the expression of NFIA by enhancing the methylation level of the NFIA promoter.

RP5-833A20.1 inhibits cell proliferation and invasion in U251 cells. As RP5-833A20.1 was downregulated in glioma tissues and suppressed the expression of NFIA, the present study then investigated the effect of RP5-833A20.1 on cell proliferation and invasion. CCK-8 assays revealed that LV-RP5-833A20.1 treatment significantly decreased the proportion of living U251 cells (Fig. 4A). The invasive capacity of the cells was investigated using Transwell assays. Compared with the control groups, the overexpression of RP5-833A20.1 inhibited the migratory ability of the U251 cells (Fig. 4B and C).
RP5-833A20.1 inhibits cell cycle progression and induces cellular apoptosis. The present study also investigated whether RP5-833A20.1 is involved in cell cycle distribution and apoptosis. FACS analysis showed a significant decrease and increase in the numbers of cells in the S and G1 phases, respectively, in the U251 cells infected with LV-RP5-833A20.1, compared with the control (Fig. 5A and B). Consistent with the FACS data, the expression of G1/S phase checkpoint proteins, including tumor suppressor p53 (P53) (34), cell cycle regulator p21 (P21) (35) and plasminogen activator inhibitor 1 (PAI-1) (36) were markedly upregulated in the cells infected with LV- RP5-833A20.1 (Fig. 5C). To determine whether RP5-833A20.1 has a function in cell apoptosis, flow cytometry was performed. As shown in Fig. 5D, LV- RP5-833A20.1 significantly induced the apoptotic rate of the U251 cells.

\section{Discussion}

Glioma is the most common form of primary brain tumor in adults with varying grades of malignancy and histological subtypes (37). Based on their likely cellular origins, gliomas 
can broadly be subclassified into astrocytomas, oligodendrogliomas, ependymomas and mixed tumors (38). Despite aggressive treatment approaches, and an improved understanding of its biology and underlying molecular mechanisms, successful therapeutic strategies are limited and long-term survival rates remain unsatisfactory (39-41). The key finding of the present study was that the expression of RP5-833A20.1 was decreased in glioma tissues, compared with corresponding adjacent nontumor tissues from 20 patients with glioma. The results of the present study showed the pathological roles of RP5-833A20.1 in repressing cell proliferation, inhibiting cell cycle progression and inducing apoptosis. Thus, the results of the present study indicated that RP5-833A20.1 acts as an anti-oncogene in glioma and can be considered as a potential prognostic indicator for glioma.

Previous studies on novel lncRNAs have suggested that lncRNAs are characterized and important in the pathogenesis of cancer, rather than transcriptional noise (42-44). Accumulating evidence has shown that lncRNAs can drive carcinogenesis by promoting cell proliferation through the regulation of cell cycle and apoptosis $(17,19,45)$. Studies have found that IncRNAs can be used in predicting survival rates in patients with glioma (46), and are potential biomarkers and therapeutic targets for glioma $(47,48)$. However, the roles of lncRNAs in glioma remain to be fully elucidated. In the present study, the expression of RP5-833A20.1 was downregulated in glioma tissues, compared with corresponding adjacent nontumor tissues. Furthermore, the overexpression of RP5-833A20.1 inhibited proliferation and cell cycle progression, and induced apoptosis in U251 cells. Studies have indicated that NFIA is involved in and may be central to a variety of biological processes through complicated mechanisms in glioma $(22,23)$. In the present study, it was found that the expression of NFIA was downregulated in glioma tissues, compared with corresponding adjacent nontumor tissues. In addition, the overexpression of RP5-833A20.1 suppressed the expression of NFIA in U251 cells. Lee et al (25) identified a novel, tumor-promoting role for NFIA in glioblastoma, which was mediated via the transcriptional repression of p53, p21 and PAI1 through specific NFIA-recognition sequences in their promoters. In the present study, the results revealed that P53, P21 and PAI-1 were markedly upregulated in U251 cells overexpressing RP5-833A20.1. Therefore, RP5-833A20.1 may enhance the levels of P53, P21 and PAI-1 by suppressing the expression of NFIA.

Previous reports have demonstrated that lncRNAs exert regulatory control on gene function through their interaction with miRNAs, a family of small non-coding RNAs, which are important post-transcriptional regulators of gene expression (49-51). Based on these findings, the present study examine the potential roles of lncRNAs in binding to and regulating miRNAs. In our previous study, it was confirmed that hsa-miR-382-5p is involved in regulating the expression of NFIA by RP5-833A20.1 (27). The results of the present study showed that the overexpression of RP5-833A20.1 suppressed the expression of NFIA in U251 cells. In addition, the level of miR-382-5p was increased by the overexpression of RP5-833A20.1 in the U251 cells. Taken together, these results indicated that RP5-833A20.1 may suppress the expression of NFIA by promoting the expression of miR-382-5p in
U251 cells. However, whether other miRNAs can be regulated by RP5-833A20.1, and whether glioma can be affected by miR-382-5p through other targets remain to be elucidate, requiring further investigation. IncRNAs have dynamic effects in transcriptional regulation, and are involved in several human diseases, particularly cancer (52). For example, lincRNA-p21 prevents reprogramming by sustaining $\mathrm{CpG}$ methylation of pluripotency gene promoters (32). The present study investigated the potential roles of RP5-833A20.1 in methylation. The results revealed that the knockdown of RP5-833A20.1 decreased the level of NFIA promoter methylation. Taken together, these results indicated that RP5-833A20.1 may repress the expression of NFIA by enhancing the methylation level of the NFIA promoter. However, the detailed mechanisms of this process require further investigation.

In conclusion, the results of the present study demonstrated RP5-833A20.1 as an anti-oncogene, which inhibited tumor cell proliferation, induced apoptosis and inhibited cell cycle progression, and may involve the NFIA pathway. In addition, RP5-833A20.1 may suppress the expression of NFIA by promoting the expression of miR-382-5p or enhancing the methylation level of the NFIA promoter. These findings indicated RP5-833A20.1 as a tumor suppressor, the downregulation of which may promote glioma metastasis, and suggested that RP5-833A20.1 may be an effective target for glioma therapy.

\section{Acknowledgements}

This study was financially supported by the National Natural Sciences Foundation of China (grant no. 81301489), the President Foundation of Nanfang Hospital, Southern Medical University (grantnos.2012B002 and 2014C016), the Guangdong Provincial Medical research foundation (B2014245) and the Guangdong Provincial Department of Education Science and Technology Innovation Project (grant no. 2012KJCX0029). The funding bodies were not involved in the study design, data collection and analysis, decision to publish or preparation of the manuscript.

\section{References}

1. Torre LA, Bray F, Siegel RL, Ferlay J, Lortet-Tieulent J and Jemal A: Global cancer statistics, 2012. CA Cancer J Clin 65: 87-108, 2015.

2. Trabelsi S, Brahim DH, Ladib M, Mama N, Harrabi I, Tlili K, Yacoubi MT, Krifa H, Hmissa S, Saad A and Mokni M: Glioma epidemiology in the central Tunisian population: 1993-2012. Asian Pac J Cancer Prev 15: 8753-8757, 2014.

3. Ostrom QT, Gittleman H, Stetson L, Virk SM and Barnholtz-Sloan JS: Epidemiology of gliomas. Cancer Treat Res 163: 1-14, 2015.

4. Masamha CP, Xia Z, Yang J, Albrecht TR, Li M, Shyu AB, Li W and Wagner EJ: CFIm25 links alternative polyadenylation to glioblastoma tumour suppression. Nature 510: 412-416, 2014.

5. Liang WZ, Chou CT, Chang HT, Cheng JS, Kuo DH, Ko KC, Chiang NN, Wu RF, Shieh P and Jan CR: The mechanism of honokiol-induced intracellular $\mathrm{Ca}(2+)$ rises and apoptosis in human glioblastoma cells. Chem Biol Interac 221: 13-23, 2014.

6. Que T, Song Y, Liu Z, Zheng S, Long H, Li Z, Liu Y, Wang G, Liu Y, Zhou J, et al: Decreased miRNA-637 is an unfavorable prognosis marker and promotes glioma cell growth, migration and invasion via direct targeting Akt1. Oncogene 34: 4952-4963, 2015.

7. Bian EB, Li J, Xie YS, Zong G, Li J and Zhao B: LncRNAs: New players in gliomas, with special emphasis on the interaction of lncRNAs With EZH2. J Cell Physiol 230: 496-503, 2015. 
8. Guo $\mathrm{H}, \mathrm{Wu}$ L, Yang $\mathrm{Q}$, Ye $\mathrm{M}$ and Zhu X: Functional linc-POU3F3 is overexpressed and contributes to tumorigenesis in glioma. Gene 554: 114-119, 2015.

9. Gupta RA, Shah N, Wang KC, Kim J, Horlings HM, Wong DJ, Tsai MC, Hung T, Argani P, Rinn JL, et al: Long non-coding RNA HOTAIR reprograms chromatin state to promote cancer metastasis. Nature 464: 1071-1076, 2010.

10. Faghihi MA, Modarresi F, Khalil AM, Wood DE, Sahagan BG, Morgan TE, Finch CE, St Laurent G III, Kenny PJ and Wahlestedt C: Expression of a noncoding RNA is elevated in Alzheimer's disease and drives rapid feed-forward regulation of beta-secretase. Nat Med 14: 723-730, 2008.

11. Arab K, Park YJ, Lindroth AM, Schäfer A, Oakes C, Weichenhan D, Lukanova A, Lundin E, Risch A, Meister M, et al: Long noncoding RNA TARID directs demethylation and activation of the tumor suppressor TCF21 via GADD45A. Mol Cell 55: 604-614, 2014.

12. Zheng S, Chen H, Wang Y, Gao W, Fu Z, Zhou Q, Jiang Y, Lin Q, Tan L, Ye H, et al: Long non-coding RNA LOC389641 promotes progression of pancreatic ductal adenocarcinoma and increases cell invasion by regulating E-cadherin in a TNFRSF10A-related manner. Cancer Lett 371: 354-365, 2016.

13. Nie W, Ge HJ, Yang XQ, Sun X, Huang H, Tao X, Chen WS and $\mathrm{Li} \mathrm{B}$ : LncRNA-UCA1 exerts oncogenic functions in non-small cell lung cancer by targeting miR-193a-3p. Cancer Lett 371: 99-106, 2016.

14. Schoenherr CJ, Levorse JM and Tilghman SM: . Nat Genet 33 66-69, 2003

15. Lee JT: The $\mathrm{X}$ as model for RNA's niche in epigenomic regulation. Cold Spring Harb Perspect Biol 2: a003749, 2010.

16. Kino T, Hurt DE, Ichijo T, Nader $\mathrm{N}$ and Chrousos GP: Noncoding RNA gas5 is a growth arrest- and starvation-associated repressor of the glucocorticoid receptor. Sci Signal 3: ra8, 2010.

17. Fan Y, Shen B, Tan M, Mu X, Qin Y, Zhang F and Liu Y: TGF-beta-induced upregulation of malat1 promotes bladder cancer metastasis by associating with suz12. Clin Cancer Res 20: 1531-1541, 2014

18. Garding A, Bhattacharya N, Claus R, Ruppel M, Tschuch C, Filarsky K, Idler I, Zucknick M, Caudron-Herger M, Oakes C, et al: Epigenetic upregulation of lncRNAs at $13 \mathrm{q}$ is linked to the In Cis downregulation of a gene cluster that targets NF-kB. PLoS Genet 9: e1003373, 2013

19. Kim T, Jeon YJ, Cui R, Lee JH, Peng Y, Kim SH, Tili E, Alder $\mathrm{H}$ and Croce CM: Role of MYC-regulated long noncoding RNAs in cell cycle regulation and tumorigenesis. J Natl Cancer Inst 107: dju505, 2015.

20. Zhang JX, Han L, Bao ZS, Wang YY, Chen LY, Yan W, Yu SZ Pu PY, Liu N, You YP, et al: HOTAIR, a cell cycle-associated long noncoding RNA and a strong predictor of survival, is preferentially expressed in classical and mesenchymal glioma. Neuro Oncol 15: 1595-1603, 2013.

21. Shi Y, Wang Y, Luan W, Wang P, Tao T, Zhang J, Qian J, Liu N and You Y: Long non-coding RNA H19 promotes glioma cell invasion by deriving miR-675. PLoS One 9: e86295, 2014.

22. Song HR, Gonzalez-Gomez I, Suh GS, Commins DL, Sposto R, Gilles FH, Deneen B and Erdreich-Epstein A: Uclear factor IA is expressed in astrocytomas and is associated with improved survival. Neuro Oncol 12: 122-132, 2010

23. Glasgow SM, Zhu W, Stolt CC, Huang TW, Chen F, LoTurco JJ, Neul JL, Wegner M, Mohila C and Deneen B: Mutual antagonism between Sox10 and NFIA regulates diversification of glial lineages and glioma subtypes. Nat Neurosci 17: 1322-1329, 2014.

24. Brun M, Coles JE, Monckton EA, Glubrecht DD, Bisgrove D and Godbout R: Nuclear factor I regulates brain fatty acid-binding protein and glial fibrillary acidic protein gene expression in malignant glioma cell lines. J Mol Biol 391: 282-300, 2009.

25. Lee JS, Xiao J, Patel P, Schade J, Wan J, Deneen B, Erdreich-Epstein A and Song HR: A novel tumor-promoting role for nuclear factor IA in glioblastomas is mediated through negative regulation of p53, p21 and PAI1. Neuro Oncol 16: 191-203, 2014

26. Glasgow SM, Laug D, Brawley VS, Zhang Z, Corder A, Yin Z, Wong ST, Li XN, Foster AE, Ahmed N and Deneen B: The miR-223/nuclear factor I-A axis regulates glial precursor proliferation and tumorigenesis in the CNS. J Neurosci 33: $13560-13568,2013$
27. Hu YW, Zhao JY, Li SF, Huang JL, Qiu YR, Ma X, Wu SG, Chen ZP, Hu YR, Yang JY, et al: RP5-833A20.1/miR-382-5p/NFIA-Dependent Signal transduction pathway contributes to the regulation of cholesterol homeostasis and inflammatory reaction. Arterioscler Thromb Vasc Biol 35: 87-101, 2015.

28. Cao C, Sun J, Zhang D, Guo X, Xie L, Li X, Wu D and Liu L: The long intergenic noncoding rna ufc1, a target of MicroRNA 34a, interacts with the mRNA stabilizing protein HuR to increase levels of $\beta$-Catenin in HCC cells. Gastroenterology 148: 415-426 e18, 2015

29. Hirata H, Hinoda Y, Shahryari V, Deng G, Nakajima K, Tabatabai ZL, Ishii $\mathrm{N}$ and Dahiya R: Long noncoding RNA MALAT1 promotes aggressive renal cell carcinoma through Ezh2 and interacts with miR-205. Cancer Res 75: 1322-1331, 2015.

30. Hu YW, Ma X, Li XX, Liu XH, Xiao J, Mo ZC, Xiang J, Liao DF and Tang CK: Eicosapentaenoic acid reduces ABCA1 serine phosphorylation and impairs ABCA1-dependent cholesterol efflux through cyclic AMP/protein kinase a signaling pathway in THP-1 macrophage-derived foam cells. Atherosclerosis 204: e35-e43, 2009.

31. Livak KJ and Schmittgen TD: Analysis of relative gene expression data using real-time quantitative PCR and the 2(-Delta Delta C(T)) method. Methods 25: 402-408, 2001.

32. Bao X, Wu H, Zhu X, Guo X, Hutchins AP, Luo Z, Song H, Chen Y, Lai K, Yin M, et al: The p53-induced lincRNA-p21 derails somatic cell reprogramming by sustaining $\mathrm{H} 3 \mathrm{~K} 9 \mathrm{me} 3$ and $\mathrm{CpG}$ methylation at pluripotency gene promoters. Cell Res 25: 80-92, 2015.

33. Lai $\mathrm{F}$ and Shiekhattar R: Where long noncoding RNAs meet DNA methylation. Cell Res 24: 263-264, 2014.

34. Hao PP, Li H, Lee MJ, Wang YP, Kim JH, Yu GR, Lee SY, Leem SH, Jang KY and Kim DG: Disruption of a regulatory loop between DUSP1 and p53 contributes to hepatocellular carcinoma development and progression. J Hepatol 62: 1278-1286, 2015.

35. Ehedego H, Boekschoten MV, Hu W, Doler C, Haybaeck J, Gaßler N, Müller M, Liedtke C and Trautwein C: p21 ablation in liver enhances DNA damage, cholestasis and carcinogenesis. Cancer Res 75: 1144-1155, 2015.

36. Giacoia EG, Miyake M, Lawton A, Goodison S and Rosser CJ: PAI-1 leads to G1-phase cell-cycle progression through cyclin D3/cdk4/6 upregulation. Mol Cancer Res 12: 322-334, 2014.

37. Zhang S, Ye Z, Song X, Chen G, Huai C, Wang Q, Song J, Lu D, Zhao Y and Chen H: Association of EFEMP1 gene polymorphisms with the risk of glioma: A hospital-based case-control study in a Chinese Han population. J Neurol Sci 349: 54-59, 2015.

38. Qureshi IA and Mehler MF: Emerging roles of non-coding RNAs in brain evolution, development, plasticity and disease. Nat Rev Neurosci 13: 528-541, 2012

39. Zhang XQ and Leung GK: Long non-coding RNAs in glioma: Functional roles and clinical perspectives. Neurochem Int 77: 78-85, 2014.

40. Morfouace M, Lalier L, Oliver L, Cheray M, Pecqueur C, Cartron PF and Vallette FM: Control of glioma cell death and differentiation by PKM2-Oct4 interaction. Cell Death Dis 5: e1036, 2014.

41. Ellis BC, Molloy PL and Graham LD: CRNDE: A long non-coding rna involved in cancer, neurobiology and development. Front Genet 3: 270, 2012.

42. Mattick JS, and Rinn JL: Discovery and annotation of long noncoding RNAs. Nat Struct Mol Biol 22: 5-7, 2015.

43. Yan B, Yao J, Liu JY, Li XM, Wang XQ, Li YJ, Tao ZF, Song YC, Chen Q and Jiang Q: LncRNA-MIAT regulates microvascular dysfunction by functioning as a competing endogenous RNA. Circ Res 116: 1143-1156, 2015 .

44. Yu H, Xu Q, Liu F, Ye X, Wang J and Meng X: Identification and validation of long non-coding RNA biomarkers in human non-small cell lung carcinomas. J Thorac Oncol 10: 645-654, 2015.

45. Pandey GK, Mitra S, Subhash S, Hertwig F, Kanduri M, Mishra K, Fransson S, Ganeshram A, Mondal T, Bandaru S, etal: The risk-associated long noncoding RNA NBAT-1 controls neuroblastoma progression by regulating cell proliferation and neuronal differentiation. Cancer Cell 26: 722-737, 2014.

46. Zhang XQ, Sun S, Lam KF, Kiang KM, Pu JK, Ho AS, Lui WM, Fung CF, Wong TS and Leung GK: A long non-coding RNA signature in glioblastoma multiforme predicts survival. Neurobiol Dis 58: 123-131, 2013. 
47. Sun Y, Wang Z and Zhou D: Long non-coding RNAs as potential biomarkers and therapeutic targets for gliomas. Med Hypotheses 81: 319-321, 2013.

48. Yao J, Zhou B, Zhang J, Geng P, Liu K, Zhu Y and Zhu W: A new tumor suppressor LncRNA ADAMTS9-AS2 is regulated by DNMT1 and inhibits migration of glioma cells. Tumour Biol 35: 7935-7944, 2014.

49. Imig J, Brunschweiger A, Brümmer A, Guennewig B Mittal N, Kishore S, Tsikrika P, Gerber AP, Zavolan M and Hall J: miR-CLIP capture of a miRNA targetome uncovers a lincRNA H19-miR-106a interaction. Nat Chem Biol 11: 107-114, 2015.
50. Chen CL, Tseng YW, Wu JC, Chen GY, Lin KC, Hwang SM and Hu YC: Suppression of hepatocellular carcinoma by baculovirus-mediated expression of long non-coding RNA PTENP1 and MicroRNA regulation. Biomaterials 44: 71-81, 2015.

51. Dey BK, Pfeifer K and Dutta A: The H19 long noncoding RNA gives rise to microRNAs miR-675-3p and miR-675-5p to promote skeletal muscle differentiation and regeneration. Genes Dev 28: 491-501, 2014

52. Ning $X$, Shi Z, Liu X, Zhang A, Han L, Jiang K, Kang $C$ and Zhang Q: DNMT1 and EZH2 mediated methylation silences the microRNA-200b/a/429 gene and promotes tumor progression. Cancer Lett 359: 198-205, 2015. 